Instructions for authors, subscriptions and further details:

\title{
http://rimcis.hipatiapress.com
}

\section{Power and Cultures of the World. Developing New Social Architectures of Influence in the UN: A Network Analysis}

Livia García-Faroldi ${ }^{1}$, Valeria Bello²

1) University of Málaga, Spain

2) University Ramon Llull, Spain

Date of publication: online first on 28 October 2020, Issue published 30 March 2021

Edition period: March 2021 - July 2021

To cite this article: García-Faroldi, L., \& Bello, V. (2021). Power and Cultures of the World. Developing New Social Architectures of Influence in the UN: A Network Analysis. International and Multidisciplinary Journal of Social Sciences, 10(1), 1-29. doi: 10.17583/rimcis.2021.5248 To link this article: http://doi.org/10.17583/rimcis.2021.5248

\section{PLEASE SCROLL DOWN FOR ARTICLE}

The terms and conditions of use are related to the Open Journal System and to Creative Commons Attribution License(CC-BY). 


\section{Power and Cultures of the World. Developing New Social Architectures of Influence in the UN: A Network Analysis}

Livia García-Faroldi

University of Málaga
Valeria Bello

University Ramon Llull

\section{Abstract}

The most important sociologists have discussed whether it is the social structure that produces individual behaviours or the latters are only the results of individuals' will. In the literature of international relations, as well, a similar debate about the structureagency problem has developed: in this context, the central question is whether or not there exist external sources of influences for the decisions that states take in international politics. This article, by sharing an integrative and post-structural approach (Archer, 1995; Foucault, 1970) proposes an empirical analysis of the formation of power architectures within the UN-SC surrounding the question of Intercultural Dialogue. A Social Network Analysis checks whether the way actors exercise power is concurrently the result of individual wills whose contents follows both institutional and cultural conditioning. Findings show that there is not a fixed structure of power relations which can be given for granted but it is continuously negotiated through both practices and social interactions. However, both institutional and, above all, cultural factors shape power relations.

Keywords: intercultural dialogue, power, social network analysis, international relations, culture 


\section{Poder y Culturas del Mundo.}

\section{Desarrollando Nuevas Arquitecturas Sociales de Influencia en Naciones Unidas: Un Análisis de Redes}

\author{
Livia García-Faroldi \\ University of Málaga
}

\author{
Valeria Bello \\ University Ramon Llull
}

\section{Resumen}

Los sociólogos más importantes han discutido si es la estructura social la que produce los comportamientos individuales o si estos últimos son el resultado de la voluntad de los sujetos. También en la literatura sobre relaciones internacionales se ha desarrollado un debate similar sobre el problema agencia-estructura: en este contexto, la pregunta es si existe o no fuentes externas de influencia en las decisiones que los Estados toman en política internacional. Este artículo propone un análisis empírico de la formación de estructuras de poder dentro del Consejo de Seguridad de las Naciones Unidas alrededor de la cuestión del diálogo intercultural. Utilizando el análisis de redes sociales, se contrasta si el modo en que los actores ejercen poder es simultáneamente el resultado de voluntades individuales cuyos contenidos están condicionados institucional y culturalmente. Los resultados muestran que no hay una estructura de las relaciones de poder fija y que pueda darse por supuesta, sino que es continuamente negociada a través de prácticas e interacciones sociales. Sin embargo, tanto los factores institucionales como, sobre todo, los culturales modelan las relaciones de poder.

Palabras clave: diálogo intercultural, poder, análisis de redes sociales, relaciones internacionales, cultura 
nalyzing power and the way it is exercised inevitably means to take a decision about whether it relies on individual characteristics only or, vice versa, social structures are sources of influence actually limiting or even shaping power relations. In such a light, the structure-agency problem is probably the sociological theme per excellence. On it, the most important sociologists of all times have formulated theories, with the aim of explaining whether it is the social structure that produces individual behaviors or the latters are only the results of individuals own will. This simplistic summary of the matter of discussion does not make justice to the complexity of the debate that has developed since the 1970s, when scholarship has started to focus on approaches that combine both views. These take into account social architectures concurrently shaping and shaped by individual decisions, through what literature reviews now calls integrative and post-structuralist theories (Elder-Vass, 2010; Archer, 2013). In light of this, by underlying the dialectic tensions existing between structure and agency, sociologists such as Giddens (1979, 1990), Bourdieu (1990a, 1990b), Foucault (1970, 1979), have respectively identified in social interactions, social practices and discourses those sources that intervene in the process of mutual influence taking place between structure and agency. Consequently, the formation of discourses and how they interact with social interactions and practices at international level is a crucial case study for international sociology; it shows the sort of influences occurring at international level that affect societies globally.

This is particularly the case of the discourses surrounding Intercultural Dialogue. This concept has developed recently at the international level (Bello \& Bloom, 2017) and some important research (Kymlicka, 2012) has recognized in some international discourses, particularly in the UN, an attempt to replace the concept of multiculturalism, discredited in the last decade for being responsible, according to some, of the lack of integration of migrants (Vertovec \& Wessendorf, 2010). A variety of works on Interculturalism have currently identified in the importance of dialogue and communications included in this framework its differences with multiculturalism, particularly as it concerns interethnic and intercommunity relations and the integration of migrants (Bello \& Bloom, 2017; Meer \& Modood, 2012; Sze \& Powell, 2004).

Due to the inextricable way that the reply to the structure-agency problem shapes approaches to concepts of power, it is not surprising that, similarly, in the domain of international relations all school of thoughts, from realism, to 


\section{Garcia-Faroldi \& Bello-Power and Cultures of the World}

liberalism and constructivism, have also engaged with discussions around whether or not structures influence states ' international politics (Dunne et al., 2007). While classic realism considers that states behave in an anarchical environment where power depends on material resources, such as capital, arms, and land resources (Waltz, 1990; Goldstein \& Pevehouse, 2006), all other schools admit the existence of some sorts of structures in which states' decisions are given. The difference among approaches lies mostly in the variety of these structures, whether formed by institutions or cultures. At closer inspection, however, also integrative and post-structuralist sociological theories weight the relevance of both institutional and cultural conditioning on the life of society (Archer, 2013).

Taking into account the parallelism between these two debates, those who write consider that looking at ways power is exercised within networks at supranational level offers a unique opportunity for replying to such a puzzle: it enables to both understand those processes shaping power relations among states and interpret institutional and cultural conditioning occurring in the international domain, as architectures that possibly affect international strategies. In such a light, this article analyses the network of relations formed around the discussion of intercultural dialogue, which is a theme that the United Nations (UN) have been developing mainly from 2000 and which is connected with questions of international security and the topical concern of international terrorism.

The article first reviews how structural and institutional conditionings have found a fertile ground of discussion in international relations thanks to sociological approaches to international and security studies. Secondly, it investigates empirically, with a social network analysis, the formation of power architectures within the UN-SCs urrounding the question of Intercultural Dialogue. It concludes by highlighting that there is not such a fixed structure of power relations which can be given for granted but its architecture is continuously negotiated through both practices and social interactions, in which the role of cultures is far more evident in the discussions happening within the UN than one would expect. 


\section{Cultural and Structural Conditionings in Power Relations}

In considering the "Causal Power of Social Structures", Elder-Vass (2010) has highlighted how in sociology there has been a long debate between those scholars and schools of thoughts advocating the role of social structures as determinants of individual behaviours and those relying on methodological individualism and insisting on the role of individuals' free choice. Several perspectives have been developed in order to solve what is now known as "the structure-agency problem".

However, the most prominent perspectives on this question are those that Giddens, on the one hand, and Bourdieu, on the other, have developed, also known as integrative approaches or "structuration theory" (Giddens, 1979, 1991; Bourdieu, 1977, 1992); and the post-structural approach, including both Foucault's epistemological construction of the reality (Foucault, 1970); and Archer's theory of "Social Morphogenesis" (Archer, 1995, 2013). In a variety of ways, these outlooks all attempt to keep a dialectic relation between structure and agency. While Giddens (1979) insists on the role that identities and social interactions play in the processes in which structure and agency contribute to producing each other, Bourdieu emphasizes how the construction of reality depends upon social practices (Bourdieu, 1977, 1992; Swartz, 2013). Archer's morphogenesis, instead, does not conflate the two momenta. By including "time" as an intervening variable, she considers how cultural and institutional conditionings are subjacent to those singular behaviours that, through individual creativity, modify the structural circumstances in which the behaviours were initially produced. In a poststructural understanding, power is then a result of cultural and institutional conditioning (Archer, 2013). Foucault, instead, considers that the social reality constitutes itself through a dynamic of controls in which discourses embeds individuals' agency and individuals produce discourses. Power is then a discursive creation (Foucault, 1979; Weedon, 1987; Gordon, 1980).

In parallel, in the literature of international relations, an important debate about the structure-agency problem has also developed: in this context, the question is whether or not there exist external sources of influences for the decisions that states take in international politics. In mainstream perspectives, two are the most widespread approaches. According to scholars following the realist and neorealist schools of thought, states are absolutely independent 
from exogenous sources of influence when they take decisions in foreign politics. Therefore, anarchy is the central fact of the international system for them (Waltz, 1990; Goldstein \& Pevehouse, 2006; Lebow, 2007). Some neorealist, indeed, have also taken into account some sources of influence of states' politics in the structure of power - or balance of power - (Mearsheimer, 2007; Weber, 2009), which is, according to them, the result of the material resources that states have at their disposal. These material resources, in their conceptualizations, affect possible decisions of states, constituting a sort of structure for states' agency (Mearsheimer, 2007). Neoliberals or neoinstitutionalist scholars, instead, consider that, in the international system, there exist respectively market structures (Keohane \& Nye, 2001) or security institutions (Kay, 2011), which shape the decision-making process of states in foreign politics.

Alternatively to these mainstream approaches, post-positivist or poststructural perspectives (Doherty, 2000; Elias \& Sutch, 2007; Wallerstein, 1990) have recently developed new outlooks in International Relations. In particular, constructivist theorists consider that "Anarchy is what states make of it" (Wendt, 1992, 1994) and that both material and non-material resources, such as identities, values, and cultures, shape international politics and states' decisions. Wendt proposes a model of formation of international politics that is very close to current sociological integrative theories (Wendt, 1995). He claims that, through their mutual interactions, agents (states) establish practices that shape international relations and contribute to the constitution of the identity process of agents themselves. These states' identities make international relations follow certain patterns, creating expectations that scholars can study and predict. These practices can undertake socially constructed ways of functioning, with the formation of shared knowledge among states and the creation of collaborative institutions and assignment of material resources. These are at all effects social architectures that embed international relations (Wendt, 1995).

By both sharing Wendt's constructivist perspective and mixing it with Archer's post-structural understanding of the role of culture, this article claims that actors' interactions influence the architecture of interstate relations. Their agency is the result of actors' identities and, therefore, is consistent with the architectural elements forming actors' identities (both non-material and material resources). However, actors' identities are constantly but gradually 
modified through practices and social interactions, thus shaping the final strategies. The way this process is conceived is, consequently, also close to the sociological post-structuralist approaches to the structure-agency problem, and mainly to Archer's positions.

In order to understand the way socio-cultural and institutional structures act as sources of conditioning for power relations, we consider the case of the discussions happened in the UN Security Council in a meeting where its members were called to express what Intercultural Dialogue means and how it should develop. This is a particularly interesting example of negotiations at international level because the practice of Intercultural Dialogue is the core strategy used within the Alliance of Civilizations, an agency of the UN created to resolve cultural misunderstandings between UN members. Therefore, the case of this meeting on Intercultural Dialogue proves useful to analyze whether cultural elements influence the formation of alliances, or, instead, other factors are more relevant. A Social Network Analysis (SNA) empirically verifies whether mainstream approaches prove correct - if power is the result of the individual wills of actors or, vice versa, structures affect the way states shape their discourses at this official meeting -, or integrative and poststructural approaches are better suited to grasp the complexity of today's power relations, especially in a context like the $\mathrm{UN}$, in which the variety of cultural elements included in high level discussions play a crucial role. A SNA provides a sound way to understand what influenced the formations of discourses in this meeting, as it is able to show the connections between the discourses and how the network of power relations takes shape (Fernandez \& Gould, 1994; Maoz, 2011). Therefore, a SNA can actually show if culture and discourse can mutually condition the formation of a complex architecture of power relations within the UN Security Council, or if there are some other elements that constitute a fix structure of power relations.

\section{Methodology: Data Source and Creation of Data Matrix}

The case study that this work takes into account is the 6322 Meeting of the UN Security Council, which was held in May 2010 and whose agenda was the "Maintenance of International Peace and Security. Intercultural Dialogue for Peace and Security". The actors who sat at that meeting were: the five permanent members (US, Russia, China, France and the UK), the ten non- 
permanent members (Austria, Bosnia, Brazil, Gabon, Japan, Lebanon, Mexico, Nigeria, Turkey, and Uganda), and the UN Secretary- General (SG$\mathrm{UN})$. This meeting was crucial for the development of intercultural relations for maintaining international peace and security and their outcomes globally, particularly the consequent replacement of the multicultural framework in favour of the one of Interculturalism in several countries in order to smooth inter-ethnic relations within countries and bilateral relations between origin and destination countries of different ethnic communities (Bello \& Bloom, 2017). In this meeting, actually, each of the represented UN member states clarified what the concept "Intercultural Dialogue" means according to them, what actions should be undertaken to promote it and what actors should be involved in its development.

For an understanding of countries' positions, first, we developed a discourse analysis (or qualitative content analysis) of the speeches of the countries' representatives; this resulted in a list of forty-five concepts that summarize representatives' discourses. Secondly, a social network analysis identified the relations and connections between the members of the UN-SC, as a result of sharing or not some of these concepts. Actually, the SNA is able to analyze the relations (ties) between actors (nodes) and the patterns and implications of these relations. The main element that characterizes SNA is that this technique takes into account actors and their actions as interdependencies, and the links (ties) among the actors are consequently connections identified as channels of transference or "flow" of resources (both material and non-material ones) between actors (Wasserman \& Faust, 1994).

A data set composed of two subsets of data, as in the case study we have developed, is usually referred to as a "two-mode network" to reflect that the two subsets of data include information about modes (or structural features) of the data. The term "mode" indeed refers to a distinctive set of entities about which structural measures are analyzed. The actors included in the first subset have ties to concepts that are included in the other subset. Usually, one set is considered more responsible for tie creation (primary or top node set; in our study the "actors") than the other (secondary or bottom node set; in our study "the concepts") (Wasserman \& Faust, 1994). A two-mode data matrix provides information about which among the actors (members) of the Security Council (which appear in the row) are affiliated ${ }^{1}$ to the concepts, in the columns $^{2}$. This type of analysis is the most appropriate to see how the structure 
could affect the agency or if other elements can better represent a diverse formation of power relations, that is less structural and more based on cultural or discursive elements. As Hanneman and Riddle (2005, p. 284) explain:

"The tools of two-mode analysis could be applied to CSS (cognitive social structure) data to see if perceivers can be classified according to similarity in their perceptions of networks, simultaneously with classifying network images in terms of the similarity of those doing the perceiving. Units at any level of analysis (organizations and industries; nation states and civilizations; etc.) might be usefully viewed as two-mode problems".

The two-mode analysis allows to look at ways power is exercised and what are the networks that take place in the high-level context of the UN Security Council. In such a light, it offers a unique opportunity to both illustrate what truly shapes power relations among states and whether institutional and cultural conditioning occurring in the international domain constitutes architectures that possibly affect international strategies, or if indeed there is a fixed structure of power relations, that is predetermined.

The examination of the dataset of our study shows that many concepts are included in the discourses of only one or two actors, resulting in a very scattered network. This implies that only some concepts were relevant in generating a discussion within the UN-SC. Therefore, the analysis focused on a different matrix with a threshold criterion that excluded those concepts shared by less than four members of the UN-SC, so as to include in the analysis only those concepts that generated a discussion at least between a quarter of the actors involved in the meeting. With this restriction, the analysis focused only on sixteen concepts (see Table I).

As it is obvious, the discussion mostly focused on the two concepts included in the agenda of the meeting: all the actors mentioned the importance of "Intercultural Dialogue". The US representative is the only one who does not include in his speech any reference to the fact that the "Final Aim of ICD is to reach a Stable Peace and International Security". A majority of actors also refer to a third core concept, "Tolerance among Cultures", with the exclusion of the Secretary-General of the UN, Lebanon, and the UK. The representatives of these two specific countries, instead, both use the concept "Acceptance" rather than the one of tolerance. Between the two concepts there seems to be a cultural nuance. The code "Acceptance" actually describes discourses proposing a passive attitude towards something that is not 


\section{Garcia-Faroldi \& Bello - Power and Cultures of the World}

considered in line with the speaker's own position; instead, the concept "Tolerance" seems to convey a message of a more proactive attitude, with a will to deal peacefully with and clarify situations felt as inconvenient. It recognizes a possible tension or disagreement on a specific issue and is willing to engage with the other group for a peaceful resolution. Acceptance is instead a passive attitude that does not engage with the difference but accepts the distance between the two positions without attempting any resolution of the subjacent disagreement.

More than a half of the members of the UN-SC also mention another issue, which is consequently the fourth more central concept (coded as "CtD>action>AoC"). It refers to the content of the strategy of Intercultural Dialogue, which should be developed through concrete actions, such as the participation in the Alliance of Civilizations (AoC). Five countries out of sixteen (China, Gabon, Japan, Lebanon and Nigeria) do not share this position. On other issues, there is less agreement between the actors involved: the rest of the concepts are actually mentioned by less than a half of the members and the least used four concepts are far more peripheral in the discussion (only five actors mention them). These are: "Extremism", "Dialogue among Civilizations", "Involvement of religious leaders", and "Involvement of Women" in the practice of Intercultural Dialogue.

The discussion of the relations between actors as identified in the sharing or not of particular concepts will verify the argument that this article proposes. The main hypothesis is that states do not formulate their discourses according only to states' interests, but socio-cultural elements influence the contents of their speeches. These can be understood through the similarities in their discourses, which emerge as the number and type of concepts that the actors share. These similarities detect the formation of networks of influences that will affect, first, the UN-SC's position more generally and, subsequently, societies more globally. The architectural features that the model includes per each country represented in the meeting included as sources of institutional or cultural conditionings, are: geo-cultural areas, percentages of immigrants within countries, majority religion of countries, and the permanent or nonpermanent nature of membership in the UN-SC. 
Table 1.

Core concepts of the UN Security Council's members discussions in the meeting $6322^{\text {nd }}$

\begin{tabular}{|c|c|c|}
\hline Concept's code & Description & $\begin{array}{c}\text { Number of } \\
\text { occurrences }\end{array}$ \\
\hline Concept $>$ ICD & $\begin{array}{l}\text { Concept used by the State: Intercultural } \\
\text { Dialogue }\end{array}$ & 16 \\
\hline FinAim $>$ PeaSec & $\begin{array}{l}\text { Final Aim of Intercultural Dialogue as } \\
\text { identified by the State: reach a stable } \\
\text { peace and international security }\end{array}$ & 15 \\
\hline $\mathrm{CtD}>$ ToleranceAmongCultures & $\begin{array}{l}\text { Content of dialogue (or what the dialogue } \\
\text { should be about): Tolerance among } \\
\text { cultures }\end{array}$ & 13 \\
\hline $\mathrm{CtD}>$ action $>\mathrm{AoC}$ & $\begin{array}{l}\text { Content of dialogue (or what the dialogue } \\
\text { should be about): concrete actions, such } \\
\text { as the participation in the Alliance of } \\
\text { Civilizations }\end{array}$ & 11 \\
\hline CtD $>$ acceptance & $\begin{array}{l}\text { Content of dialogue (or what the dialogue } \\
\text { should be about): acceptance of different } \\
\text { perspectives and opinions }\end{array}$ & 7 \\
\hline Ptlnv $>$ Med & $\begin{array}{l}\text { Parties to be involved in the dialogue: } \\
\text { Media }\end{array}$ & 7 \\
\hline Ptlnv $>$ Mediator & $\begin{array}{l}\text { Parties to be involved in the dialogue: } \\
\text { Political Mediator }\end{array}$ & 7 \\
\hline Ptlnv>YYouth & $\begin{array}{l}\text { Parties to be involved in the dialogue: } \\
\text { Youth }\end{array}$ & 7 \\
\hline Concept $>$ AoC & $\begin{array}{l}\text { Concept used by the State: Alliance of } \\
\text { Civilizations }\end{array}$ & 6 \\
\hline CtD $>$ ToleranceWithinSocieties & $\begin{array}{l}\text { Content of dialogue (or what the dialogue } \\
\text { should be about): Tolerance within } \\
\text { societies }\end{array}$ & 6 \\
\hline $\mathrm{Ev}>2010$ Rio3ForumAC & $\begin{array}{l}\text { Event mentioned as important: Forum of } \\
\text { the Alliance of Civilizations held in Rio } \\
\text { in } 2010\end{array}$ & 6 \\
\hline Ptlnv $>$ CivSoc & $\begin{array}{l}\text { Parties to be involved in the dialogue: } \\
\text { Civil Society }\end{array}$ & 6 \\
\hline Antgns $>$ extremism & Antagonist of dialogue: extremism & 5 \\
\hline Concept $>\mathrm{DaC}$ & $\begin{array}{l}\text { Concept used by the State: Dialogue } \\
\text { among Civilizations }\end{array}$ & 5 \\
\hline Ptlnv $>$ R $>$ ChristMusl & $\begin{array}{l}\text { Parties to be involved in the dialogue: } \\
\text { Religious actors, in particular Christians } \\
\text { and Muslism }\end{array}$ & 5 \\
\hline Ptlnv $>$ Women & $\begin{array}{l}\text { Parties to be involved in the dialogue: } \\
\text { Women }\end{array}$ & 5 \\
\hline
\end{tabular}




\section{Garcia-Faroldi \& Bello-Power and Cultures of the World}

\section{Results}

\section{Two-Mode Network: Analysis of Actors and Concepts}

By showing the network of relations as emerged during the discussion developed in the 6322 Meeting of the UN-SC, Figure 1 makes clear that there exist actors and concepts more central than others. An inspection of the coreperiphery model clearly shows this division in the network. The coreperiphery model has a good value of fitness $(0.753)$, which is the correlation between the observed score and the expected score. A good value means that it is possible to distinguish a core from a periphery in the group of data observed. This procedure of analysis divides both the rows and the columns into two classes: the core is a high-density block with many connections, and the periphery is a low-density block ${ }^{3}$. As Borgatti, Everett and Johnson (2013) point out: "The core-periphery interactions are often defined by the data and are not always specified. In general, we might expect core actors to attend core events and peripheral actors attend peripheral events, although we might expect to core actors to attend some peripheral events and peripheral actors to only attend a few core events" (p. 243).

In the core part of the network, there are the three most frequently used concepts ("Intercultural Dialogue", "Peace and Security" and "Tolerance among cultures") and all the members of the UN-SC, with the exclusion of Nigeria, the US and Lebanon, which, therefore, constitute the periphery of the model. The core-periphery model already provides a crucial finding: the institutional role (permanent or non-permanent membership in the UNSC) does not affect so much who will be in the core part of the network, which identifies the most influential actors and concepts. In fact, the US, a permanent member, is in the peripheral part of the network.

These three peripheral countries, when discussing Intercultural Dialogue, use fewer concepts than almost all other actors (only five concepts). However, this fact alone does not explain their marginal role but needs to be combined with an examination of which central concepts these actors include in or exclude from their speeches. The US representative, for instance, does not maintain that Intercultural Dialogue could be considered a strategy for achieving a stable peace and security (which is the second most central concept of the discourse analysis); the representative of Lebanon, instead, 
does not consider that "Tolerance among cultures" (the third most central concept) should be one of the main content of such a Dialogue.

The case of Nigeria is different: the representative of this country mentions the three core concepts but the other two he mentions are very peripheral ("Civil Society" and "Religious actors" as parties to be involved in Intercultural Dialogue). The impact of using some extremely peripheral concepts is clear when one looks at other representatives who only include five concepts in their speeches but that do not end up being as peripheral as Nigeria, like the representative of China and the one of Gabon. This happens because they mention the three most central notions, concurrently to other two concepts that are more frequently used compared to those that the Nigerian representative includes in his speech: in the case of China, "The Role of Political Mediators in Intercultural Dialogue"; in the case of Gabon, "The Role of Mass Media”.

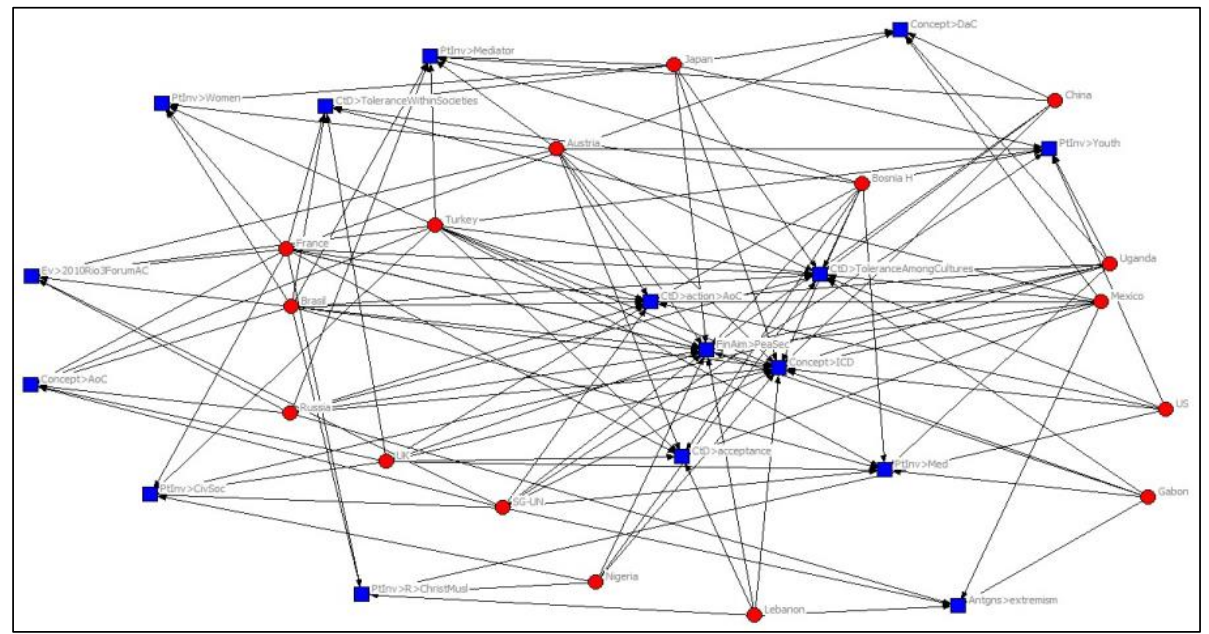

* Red circles indicate countries and blue squares indicate concepts.

Figure 1. Two-mode network: concepts used by at least $25 \%$ of members of the UN Security Council* 
To better identify the role of each state in the discussion, two measures help understand both why some concepts and actors are more central and why others, despite being more peripheral, play more of an intermediary role. These two measures are: the centrality degree (total number of ties of a node to other actors of the network) and the betweenness (total times an actor is situated in the shortest path between a pair of nodes).

Table 2.

Centrality and betweenness measures of two-mode network (ranking by centrality degree)

\begin{tabular}{|l|l|l|l|l|l|}
\hline \multicolumn{1}{|c|}{ Concept } & $\begin{array}{c}\text { Cent. } \\
\text { Deg. }\end{array}$ & Betw. & Country & $\begin{array}{c}\text { Cent.D } \\
\text { eg. }\end{array}$ & Betw. \\
\hline Concept>ICD & 1 & 0.138 & France & 0.750 & 0.087 \\
\hline FinAim>PeaSec & 0.938 & 0.117 & Turkey & 0.750 & 0.071 \\
\hline $\begin{array}{l}\text { CtD }>\text { ToleranceAmong } \\
\text { Cultures }\end{array}$ & 0.813 & 0.083 & Brazil & 0.688 & 0.066 \\
\hline CtD $>$ action $>$ AoC & 0.688 & 0.051 & Austria & 0.563 & 0.035 \\
\hline CtD $>$ acceptance & 0.438 & 0.021 & Bosnia H & 0.563 & 0.034 \\
\hline PtInv $>$ Med & 0.438 & 0.019 & SG-UN & 0.563 & 0.044 \\
\hline Ptlnv $>$ Mediator & 0.438 & 0.018 & Japan & 0.500 & 0.032 \\
\hline PtInv>Youth & 0.438 & 0.020 & Mexico & 0.500 & 0.036 \\
\hline Concept $>$ AoC & 0.375 & 0.012 & Russia & 0.500 & 0.032 \\
\hline $\begin{array}{l}\text { CtD }>\text { ToleranceWithinS } \\
\text { ocieties }\end{array}$ & 0.375 & 0.013 & UK & 0.500 & 0.028 \\
\hline Ev>2010Rio3ForumAC & 0.375 & 0.011 & Uganda & 0.500 & 0.031 \\
\hline Ptlnv $>$ CivSoc & 0.375 & 0.014 & China & 0.313 & 0.010 \\
\hline Antgns $>$ extremism & 0.313 & 0.011 & Gabon & 0.313 & 0.011 \\
\hline Concept $>$ DaC & 0.313 & 0.009 & Lebanon & 0.313 & 0.016 \\
\hline PtInv $>$ R $>$ ChristMusl & 0.313 & 0.013 & Nigeria & 0.313 & 0.011 \\
\hline Ptlnv $>$ Women & 0.313 & 0.007 & US & 0.313 & 0.012 \\
\hline
\end{tabular}

In general, in our analysis, betweenness scores are in alignment with centrality degrees, although with some nuances. It is, for instance, interesting to notice that, among members of the Security Council sharing the same number of concepts but not of the same "type", some act more frequently as bridges between different parts of the network. This is the case of: the Secretary-General of the UN, who shares with other actors as many concepts 
as Austria's representative and Bosnia's representative, but presents a higher level of betweenness; Mexico, who shows more intermediary role than Japan, Russia, UK, and Uganda, although they all hold the same centrality degree of Mexico; and Lebanon, who plays more intermediary role than countries with the same value of centrality degree, including China, Gabon, Nigeria, and the US (which are all peripheral countries).

One would wonder why does this happen. It is indeed the type of concepts they share explains this. The higher or lower centrality of the concepts that each of these actors mentions explains the actors' values of betweenness: those members of the UN-SC using concepts least shared together with more popular ones increase their capacity of brokerage. In so doing, both the Secretary-General of the UN and the Lebanon's representative refer to extremism (unlike Austria and Bosnia and Herzegovina on one side, and the rest of peripheral countries on the other). Similarly, Mexico mentions both this term and the one of "Dialogue among Civilizations", which is what makes Mexico play a more intermediary role than Russia, whose representative also quotes "Extremism" but not "Dialogue among Civilizations" in his speech. These findings demonstrate that more than structural elements, such as a permanent status in the UNSC, or the material resources that country hold, a central role and an intermediation is possible thanks to sharing a common discourse and inclusive attitudes towards others' ideas.

For example, the concepts "Acceptance", "Media", "Political Mediator" and "Youth" share the same centrality degree, but "Acceptance" and "Youth" show higher betweenness values than the other two. This depends on the fact that some amongst the most peripheral countries in the analysis quote "Acceptance" and "Youth" and through their usage shared with central actors, connect the peripheral concepts with the core part of the discussion. In this way, these concepts also gain more relevance. When a concept plays a more intermediary role, expressed by values of betweenness, between central actors and peripheral actors of the network formed within the UNSC, it assumes more relevance than other issues at stake. An interesting case is the one of the concept related to the "Involvement of Religious actors": it holds the highest betweenness value among the four concepts with the lower centrality degrees, and it even becomes more relevant than issues coded as "AoC" and "Forum Rio" and equal to "Tolerance within Societies", although these last three concepts all have a higher centrality degree compared with 


\section{García-Faroldi \& Bello - Power and Cultures of the World}

"Involvement of Religious actors". This is due to the fact that three out of five countries giving importance to the involvement of religious actors are very peripheral actors in the network, while the other two actors sharing the concept are very central. For this reason, this issue plays the role of connecting peripheral countries with the rest of the network: it connects Lebanon, Nigeria, and the US with France and Brazil. Such an intermediary role of this cultural element clearly explains why religion and religious leaders have gained such relevance in the framework of the Alliance of Civilizations $(\mathrm{AoC})$. Shared ideas and cultural elements between actors that are very different, such as the case of Lebanon, Nigeria, the US, France and Brazil, become of prime value for achieving a result.

\section{One Mode-Network: Relations Between Actors}

A very common technique used in SNA is to convert the two-mode data into two one-mode sets of data (one of actor-by-actor ties, and one of concepts-byconcepts ties) ${ }^{5}$. This allows to see relations between actors on the one hand and the association between concepts on the other. Ties between actors in this case identify connections between each two members of the UN-SC as a measure of the extent to which they share concepts emerged in the discourse analysis. Sharing at least four concepts is set as a threshold in order to take into account that a relevant connection between two countries exists ${ }^{6}$.

For an understanding of the relevance that the different members of the $\mathrm{UN}-\mathrm{SC}$ take on in the discussion of the UN-SC meeting, first, the examination of the network focuses on the role of actors. Second, the analysis takes into account the following cultural or structural factors: geo-cultural areas, immigrant percentages within countries, majority religion of countries, and for the structural ones, the permanent or non-permanent nature of membership in the UN-SC, which also reflects actors' means and power. These are the elements considered more likely to show if a convergence on a specific topic is produced, according to the literature previously mentioned.

As Figure 2 shows, there exists a great heterogeneity in the positions that countries occupy in the debate around the question of Intercultural Dialogue. Countries who are not permanent members of the UN Security Council, such as Turkey and Brazil, are very central, while some permanent members, including the UK, the US, and China, are peripheral. France stands out as the 
most central permanent member, actually holding the second maximum centrality degree, soon after Turkey. Russia and the Secretary-General of the UN occupy midway positions.

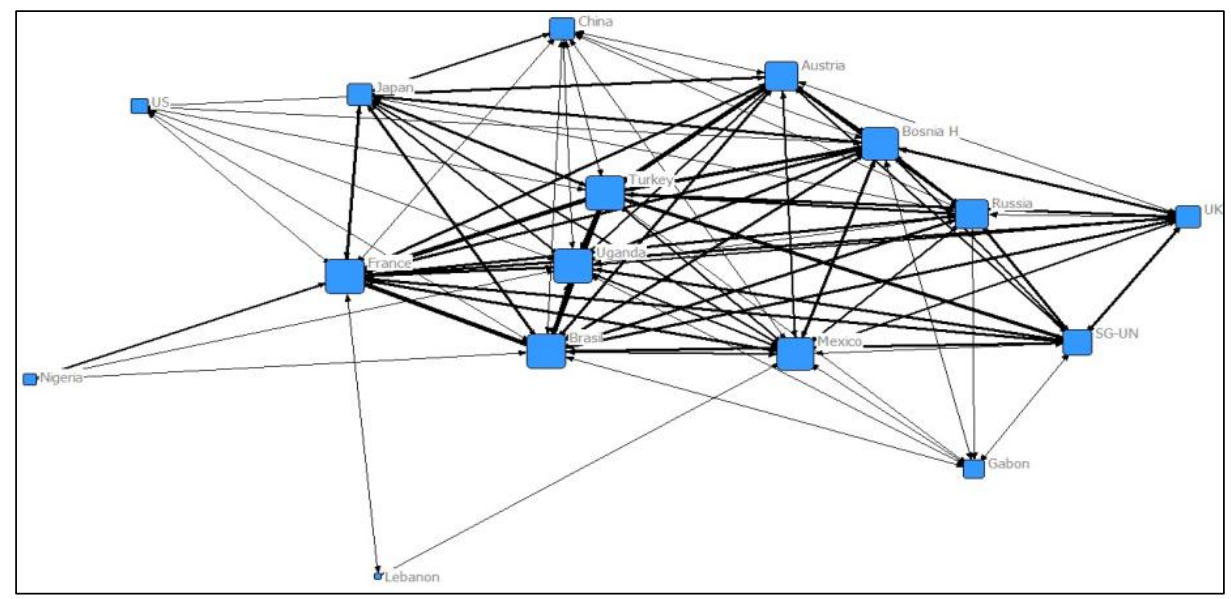

Figure 2. Centrality degree centrality of UN Security Council members (node size by centrality degree and line size by strength tie)

It is clear that there exists a variety of ways in which the actors interpret Intercultural Dialogue and particularly among the veto-holding powers in the Security Council. France is the permanent member that shows greatest interest in this topic, sharing concepts with other countries in 86 occasions. This European country is, indeed, the main intermediary between the different concepts that the members of the UN-SC formulated, as Figure 3 shows. The US, instead, locates itself in the most isolated position, sharing concepts with other countries in twenty-four occasions only. Turkey is the actor holding more ties (ninety-one) with other members, followed by France, Brazil, Bosnia and Herzegovina, and Uganda. With the exception of this last country, African members of the Council stand in the periphery of the network.

France, Uganda, Brazil, and Turkey are connected to almost all the members with the exclusion of Gabon in the case of France and Lebanon in the other three cases, whereas Bosnia and Herzegovina is connected to almost all members, excluding Lebanon and Nigeria. On the opposite side of the 
model, Lebanon is only connected to two countries, France and Mexico, and Nigeria to four (Brazil, France, Turkey and Uganda).

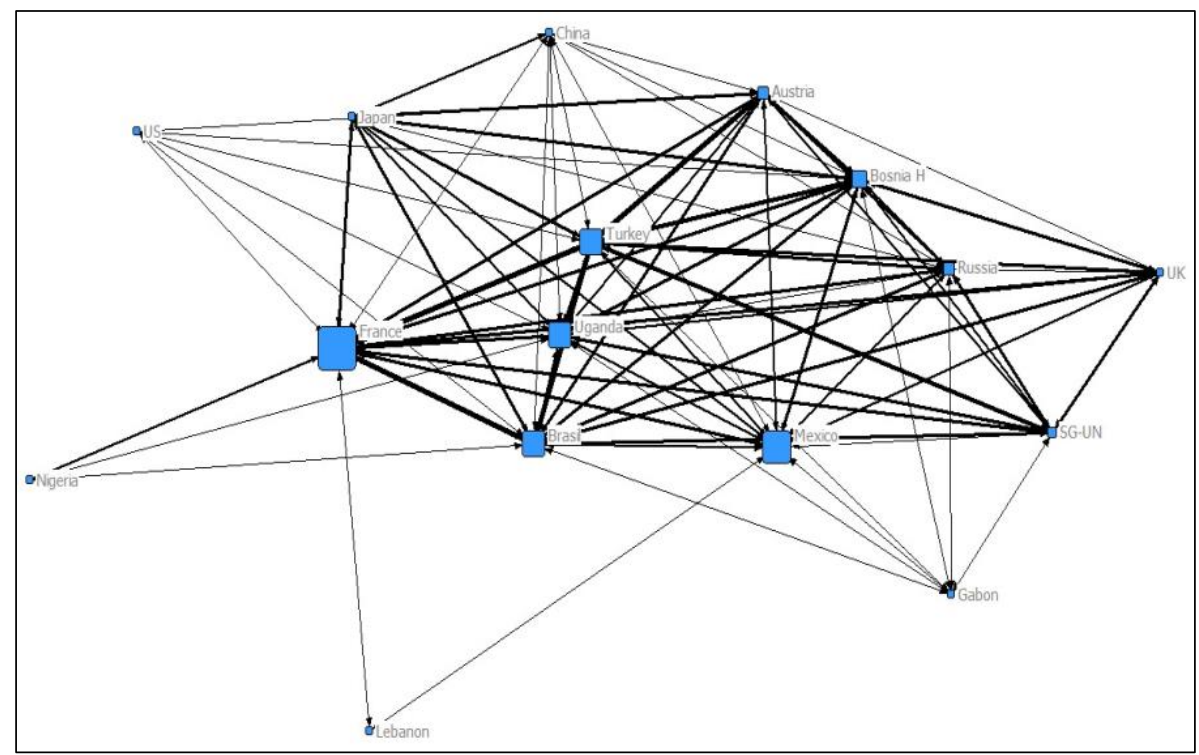

Figure 3. Betweenness centrality of UN Security Council members (node size by betweenness and line size by strength tie)

Worthing of notes are also actors' values of betweenness, a measure that calculates the extent to which actors act as brokers in the network (Figure 3). Interestingly, not all of the members sharing a higher number of concepts are those that show a more successful strategy in gaining an intermediary role in the network. This is the case of Turkey, a country that holds the highest centrality value but only occupies the third position as it relates to betweenness values, together with Uganda and Brazil. This is an interesting result due to the role that, instead, Turkey wished to play as a bridge between different cultures. Conversely, Mexico, the seventh actor in the centrality ranking, now is the second most important intermediary, following France. This is due to the fact that only Mexico and France connect the rest of the network with Lebanon. 
An examination of the co-occurrences matrix shows how many times each two actors share concepts formulated in the meeting (data under request). The maximum value of co-occurrences is nine, which happens in four occasions: Turkey with three other actors - respectively, Austria, Brazil, and France and France with Brazil. These countries had more interest in discussing this issue and thus generated more core concepts. The role of Turkey is not surprising, due to the fact that this state cosponsored the initiative of the Alliance of Civilization together with Spain (Bello \& Bloom, 2017; Bello 2017). From the findings, it becomes clear that Austria and France, both members of the EU, are also supporting this Europe-based initiative ${ }^{7}$. Austria refers to nine out of sixteen concepts and every one coincides with the concepts that Turkey has also used. Of a greater relevance is that there are two other occasions in which a country shares all its meanings with another one: the first is the case of China, which refers to the same five concepts that Japan uses (which, anyway, also quotes three more) and the second is Nigeria, which shares all its five concepts with France (but the European country presents seven more). The case of Nigeria is interesting as it shows how a country that is peripheral in this analysis is able to improve its position in the network by sharing the same discourses of Intercultural Dialogue that a country more central in the analysis holds, such as France.

The other case of co-occurrences, China-Japan, is particularly relevant for this research, because it illustrates that the geo-cultural area matters and can indeed imply similarities of discourses, strategies and coalitions, such as also the case of the support to the initiative of the AoC for European countries clearly shows. China and Japan both talk about "Tolerance among Cultures", and "The Role of Political Mediators" in the development of Intercultural Dialogue and also use the concept "Dialogue among Civilizations" (DaC). This is interesting, because the $\mathrm{DaC}$ is a term that the Former Iranian president Mohammad Khatami first used as a response to Samuel Huntington's “The Clash of Civilizations" (Huntington, 1993) ${ }^{8}$.

Looking at the content of other co-occurrences between countries, Nigeria shares with France the importance of "Tolerance among cultures" and the relevance of "Civil Society" and "Religious actors" for Intercultural Dialogue. The US, Gabon and Lebanon all share four concepts with other actors of the network. The US share four concepts with five countries: France and Brazil (the most central actors together with Turkey), Austria, Bosnia and 


\section{Garcia-Faroldi \& Bello-Power and Cultures of the World}

Herzegovina and Uganda. It is of relevance that, in general, the US position on the issue of Intercultural Dialogue is close to the one that some European countries hold. In fact, US surely belongs to the same geo-cultural area, commonly referred to as "The West". However, as previously highlighted, the US representative is the only member of the UN-SC that does not mention that the final aim of Intercultural Dialogue is to reach peace and security. Such an isolation explains why the representative of this permanent member of the $\mathrm{UN}-\mathrm{SC}$ prefers to play a marginal role in this discussion. Despite this, and in spite of their long absence in the platform of the AoC - which the US joined only some days before this 6322 meeting rather than when it was created in 2005 - the US show agreement with this initiative and, in fact, refer to concepts such as "Tolerance among Cultures" and "the content of ICD should be concrete actions, such as the Alliance of Civilizations", both shared with the five countries previously mentioned. The US give importance to the role of youth in Intercultural Dialogue, like Austria, Bosnia and Herzegovina and Uganda, and the role of "Religious actors", similarly to Brazil and France.

Lebanon, instead, is the country with the least number of co-occurrences: only France and Mexico share four concepts with this North-African country. In addition to Intercultural Dialogue and its final aim of granting peace and security, all of them emphasize the "Acceptance of different perspectives and opinions". The representative of Lebanon also shares respectively with France the interest in the involvement of "Religious actors" in the dialogue and with Mexico the concept of "Extremisms" as the main antagonist of the possibility of an Intercultural Dialogue.

The UN Secretary-General is in a central position in the network even if not the most important one. The Secretary-General (at that time Kofi Annan) shares more than three meanings with countries from different traditions and contexts, including Gabon, Mexico, Brazil, and all the European countries. Nevertheless, he does not show any relevant connection with the Asian countries (China and Japan) and neither with the US.

Figure 4 shows whether cultural or structural factors help explain the closeness or not in the positions of actors found in this network ${ }^{9}$. The analysis has incorporated measures including geographic areas, immigrant percentages, religious majorities, and whether or not the country has a permanent seat in the UN Security Council. Figure 4 clearly shows the central role that European countries play in promoting Intercultural Dialogue. All the 
European countries occupy central positions in the network, and above of all France, a permanent member of the Security Council. Turkey, a country that wishes to act as a bridge between Europe and Asia, also shares this privileged position. However, it does not achieve any relevant intermediary role. With the exception of this latter country, all these actors also have in common a Christian religious majority. They, instead, differ in their percentage of immigrants. Nevertheless, in this group of central actors we can also find countries from other geographic areas, such as Brazil, Mexico, Japan, and Uganda. These are all non-permanent members of the UN Security Council; their religion majority is Christian and all of them have smaller percentages of immigrants in their populations.

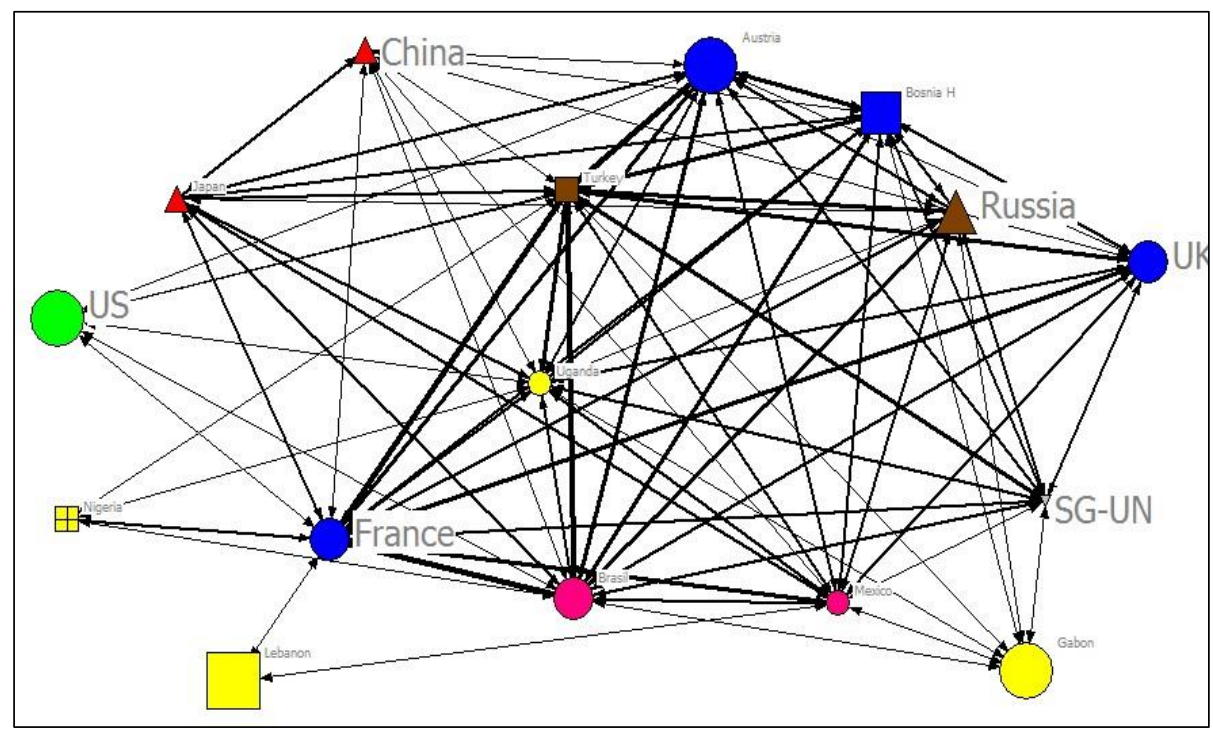

Figure 4. Social Network Analysis including Structural Factors*

* Font size: permanent seat in the UN Security Council (big), non-permanent (small). Color: Europe (blue), Africa (yellow), North America (green), South America (pink), Asia (red), between two continents (brown). Shape: Christian (circle), Muslim (square), others (up triangle), half Christian/half Muslim (Crossed-Square). Node size: more than fourteen percent of immigrants (big), from five to fourteen percent (medium), less than five percent (small). 


\section{Garcia-Faroldi \& Bello-Power and Cultures of the World}

Among the more peripheral countries in the network, China, Gabon, Lebanon, Nigeria and the US, it is worth pointing at the fact that three of them, Gabon, Nigeria, and Lebanon, share they belong to the African continent and they do not have a permanent seat in the Council. The only different cultural factor is religion: Gabon population is mainly Christian, Lebanon one's is Muslim, while in Nigeria, Christian and Muslims communities are of the same size. Gabon and Lebanon also share high percentages of immigrant populations. The other two peripheral countries, China and the US, instead, are two permanent members of the UN-SC. They do not coincide as for other structural attributes: origin, immigrant percentages or religion. Therefore, structural elements for these two countries do not affect their positions in the network. However, for both countries, structures seem to play major roles when the examination takes into account similarities of discourses.

Therefore, a geo-cultural convergence seems to play the most important role for most actors except these three permanent members of the UN-SC when one considers similarities of perspectives and interpretations of the practice of Intercultural Dialogue. The most central countries all share similar points of view about Intercultural Dialogue, are all European and Christian countries (except Turkey), with an immigration population size not exceeding 14\% (except Austria). Latin America members, also sharing some other cultural characteristics, such as religion majorities, are also very well connected to this group. Together with the US, all Western countries seem to hold similarities of discourses about Intercultural Dialogue. Japan and China also show similarities of discourses in terms of co-occurrences and African countries play all a marginal role in this model and do not achieve to get any intermediary role.

\section{Conclusions}

By taking into account whether only states' will, statuses and power influence the UN's claims or cultural and institutional conditionings also affect discourses then shaping societies more globally, this article has proposed an empirical analysis of the formation of discourses surrounding the question of Intercultural Dialogue within the UN-SC. From the findings, it is evident that the possibilities of gaining central roles and intermediary roles depend on both cultural and, at less extent, institutional factors. The case of China and Japan, 
the cohesion of European countries and the marginal role of African ones together clearly show that cultural elements explain similarities of both discourses and positions and strategies of alliances in the UN. Institutional elements play a role when combined with structural and cultural ones: the marginality of African countries is a clear example of this. In addition, institutions also allow some countries - those to which the structure of the international organization itself gives more power - to be less concerned about their position in a discussion which they do not indeed consider key for the agenda. This is clearly the case of some permanent member states, such as the US, the UK, China, and Russia. A permanent member of the UN-SC could position itself in a central or peripheral position, depending on its own will to share a centrality in the debate or not. However, the case of the US is crucial to show how, even in debating issues that the "Unipole" (Finnemore, 2008) does not perceive as really relevant for international security, cultural factors affect its discourses and final strategies; in fact, despite all scepticisms, the US supported and joined the AoC. Countries holding less power because of institutional framework, like African countries, get the possibility to improve their position in the network only by sharing dominant discourses, like the case of Nigeria.

In conclusion, some institutional but, above all, cultural elements, and mainly sharing a common discourse influence the formulations of UN's claims that subsequently involve changes for global society. The way power relations forms around specific issues is continuously negotiated and it constitutes a complex architecture that involves cultural elements, ideas and, most crucially, the ability to understand and share others' values and thus act as intermediaries between different positions for given interests at stake. More research in this direction would help understand how this complex architecture of power relations has formed in different contexts. Similar works would allow us to better comprehend how power relations can be negotiated, for the benefit of a better global governance.

\section{Competing interests}

Authors declare no competing interests in the submitted manuscript. 


\section{Garcia-Faroldi \& Bello - Power and Cultures of the World}

\section{Acknowledgments}

The authors would like to thanks Dr. Megha Amrith, Research Fellow at United Nations University, Institute on Globalizations, Culture and Mobility (UNU-GCM) for her useful comments to this text and Prof. Ainhoa de Federico de la Rua (Université de Toulouse 2) for her comments to an earlier version of this article. Livia García Faroldi would like to thank Parvati Nair, Director of United Nations University, Institute on Globalizations, Culture and Mobility (UNU-GCM) for granting a visiting fellowship, thanks to which it was possible to develop this joint research project.

\section{Funding}

Spanish Ministry of Economy and Competitiveness (Grant number CSO2017-86349-P); ERDF Andalusia Programme financed by the EU (Grant number UMA18-FEDERJA-103); Project GESTIM (BBVA Foundation, 35/2018)

\section{Notes}

${ }^{1}$ For this reason, this is also known as "affiliation" data.

${ }^{2}$ There exist only connections between the two types and not within them, as the rows send ties to the columns and not the reverse.

${ }^{3}$ On the main diagonal of the density matrix, the core has a density value of 0.944 and the periphery a density value of 0.194 .

${ }^{4}$ Acceptance is used by Lebanon and Youth by the US.

${ }^{5}$ This method does not necessarily entail loss of data when the two-mode network is also analysed (Borgatti, Everett \& Johnson, 2013).

${ }^{6}$ This is because all the countries quote "Intercultural Dialogue" and all except the US cite "Final Aim is Peace and Security". Therefore, when two members only have two or three concepts in common, they do not share considerable discourses in this meeting.

7 The EU also created a European Platform of Intercultural Dialogue, which is clearly connected with the AoC (see Bello \& Bloom, 2017). However, the UK does not show similar pattern compared to other EU countries already in 2010.

${ }^{8}$ Then, this term constituted the basic strategy of another initiative of Dialogue, which the Philippines sponsored and found quite a broad consensus for some time in Asia (Bello \& Bloom, 2017), at least until 2009.

${ }^{9}$ See Table 4 in Appendix for more details. 


\section{Appendix}

Table 3.

Centrality measures of countries in one-mode network (centrality based in the number of shared concepts, only values higher than 3)

\begin{tabular}{|l|l|l|}
\hline \multicolumn{1}{|c|}{ Ranking } & \multicolumn{1}{c|}{ Centrality degree } & \multicolumn{1}{c|}{ Betweenness } \\
\hline $\mathbf{1}$ & Turkey: 91 & France: 10.8 \\
\hline $\mathbf{2}$ & France: 86 & Mexico: 7.3 \\
\hline $\mathbf{3}$ & Brasil: 83 & Brasil: 5.1 \\
\hline $\mathbf{4}$ & Bosnia H: 74 & Turkey: 5.1 \\
\hline $\mathbf{5}$ & Uganda: 70 & Uganda: 5.1 \\
\hline $\mathbf{6}$ & Austria: 69 & Bosnia: 2.5 \\
\hline $\mathbf{7}$ & Mexico: 64 & Austria: 1.5 \\
\hline $\mathbf{8}$ & Russia: 62 & Russia: 1.3 \\
\hline $\mathbf{9}$ & SG-UN: 56 & SG-UN: 0.4 \\
\hline $\mathbf{1 0}$ & UK: 50 & China: 0 \\
\hline $\mathbf{1 1}$ & Japan: 49 & Gabon: 0 \\
\hline $\mathbf{1 2}$ & China: 37 & Japan: 0 \\
\hline $\mathbf{1 3}$ & Gabon: 28 & Lebanon: 0 \\
\hline $\mathbf{1 4}$ & US: 24 & Nigeria: 0 \\
\hline $\mathbf{1 5}$ & Nigeria: 17 & UK: 0 \\
\hline $\mathbf{1 6}$ & Lebanon: 8 & US: 0 \\
\hline Mean & 54.2 & 2.4 \\
Std. Dev. & 24.6 & 3.2 \\
Minimum & 8 & 0 \\
Maximum & 91 & 10.8 \\
Network \\
centralization*
\end{tabular}

* For valued, data, centralization statistic centrality degree is divided by the maximum value in the input dataset. Betweenness is calculated for binary data, not for valued data. 
26 Garcia-Faroldi \& Bello-Power and Cultures of the World

Table 4.

Majority religion and percentage of immigrants*

\begin{tabular}{|l|l|c|}
\hline \multicolumn{1}{|c|}{ Country } & Religion Majority & Immigrant Percentages 2010 \\
\hline Austria & Christian & 15.7 \\
\hline $\begin{array}{l}\text { Bosnia and } \\
\text { Herzegovina }\end{array}$ & Muslim & 0.6( \\
\hline Brazil & Christian & 0. \\
\hline China & Other/Atheist & 0.1 \\
\hline France & Christian & 11.6 \\
\hline Gabon & Christian & 23.6 \\
\hline Japan & Other & 1.9 \\
\hline Lebanon & Muslim & 17 \\
\hline Mexico & Christian & 0.9 \\
\hline Nigeria & Christian and & 0.7 \\
\hline Russia & Muslim & 7.7 \\
\hline Secretary-General & Other/Atheist & N/A \\
\hline Turkey & Muslim & Applicable) \\
\hline United Kingdom & Christian & 2.5 \\
\hline $\begin{array}{l}\text { United States of } \\
\text { America }\end{array}$ & Christian & 12.4 \\
\hline Uganda & & 14.3 \\
\hline
\end{tabular}

* Data taken from the OECD database. Immigrant percentage: low (1) less than 7, medium (2), 7 to 14; high (3) more than 14.

\section{References}

Archer, M. (1982). Morphogenesis versus structuration: on combining structure and action. British Journal of Sociology, 33(4), 455-483.

Archer, M. (1988). Culture and agency: the place of culture in social theory. Cambridge University Press.

Archer, M. (1995). Realist social theory: the morphogenetic approach. Cambridge University Press.

Archer, M. (ed.) (2013). Social Morphogenesis. Springer. 
Bello, V. (2017). Interculturalism as a New Framework to Reduce Prejudice in Times of Crises in European Countries. International Migration, 55(2), 23-38. https://doi.org/10.1111/imig.12262

Bello, V., \& Bloom, T. (2017). Interculturalism in Time of Crises: An

Introduction. International Migration, 55(2), 5-9.

https://doi.org/10.1111/imig.12260

Borgatti, S., Everett, M., \& Johnson, J. (2013). Analyzing Social Networks.

SAGE Publications.

Bourdieu, P. (1977). Outline of a Theory of Practice. Cambridge University

Press. 2013 Translation by Richard Nice.

Bourdieu, P. (1990a). In Other Words. Polity.

Bourdieu, P. (1990b). The Logic of Practice. Polity.

Bourdieu, P. (1992). Thinking about Limits. Theory, Culture and Society, 9(1), 37-49. https://doi.org/10.1177/026327692009001003.

Doherty, E. (2000). Negotiating Across Disciplines: The implications of judgment and decision-making research for international relations theory. In E. Doherty \& R. Sil (Eds.), Beyond boundaries? disciplines, paradigms, and theoretical integration in international studies (pp. 31-57). SUNY Press.

Dunne, T., Kurki, M., \& Smith, S. (Eds.) (2007). International Relations Theories: Discipline and Diversity. Oxford University Press.

Elder-Vass, D. (2010). The Causal Power of Social Structures: Emergence,

Structure and Agency. Cambridge University Press.

Elias, J., \& Sutch, P. (2007). International relations: the basics. Routledge. Fernandez, R., \& Gould, R. (1994). A Dilemma of State Power: Brokerage and Influence in the National Health Policy Domain. American Journal of Sociology, 99, 1455-1491.

Finnemore, M. (2008). Legitimacy, Hypocrisy, and the Social Structure of Unipolarity. World Politics, 61(1), 58-85.

https://doi.org/10.1017/S0043887109000082

Foucault, M. (1970). The Order of Things. Routledge.

Foucault, M. (1979). Discipline and Punish: The Birth of the Prison. Penguin Books.

Giddens, A. (1979). Central problems in Social Theory: Action, Structure and Contradiction in Social Analysis. Macmillan.

Giddens, A. (1990). The Consequences of Modernity. Polity. 
28 Garcia-Faroldi \& Bello-Power and Cultures of the World

Giddens, A. (1991). Modernity and Self-Identity. Self and Society in the Late Modern Age. Polity.

Goldstein, J., \& Pevehouse, J. (2006). International Relations, 7th Ed.

Pearson Longman.

Gordon, C. (Ed.) (1980). POWER/KNOWLEDGE. Selected Interviews and Other Writings 1972-1977 by Michel Foucault. Pantheon Books.

Hanneman, R., \& Riddle, M. (2005). Introduction to Social Network Analysis. University of California.

Huntington, S. (1993). The Clash of Civilizations? Foreign Affairs 72, 2249. https://doi.org/10.2307/20045621

Kay, S. (2011). Global Security in the Twenty-First Century: The Quest for Power and the Search for Peace. Rowman \& Littlefield.

Keohane, R., \& Nye, J. (2001). Power and Interdependence. Longman.

Kymlicka, W. (2012). Comment on Meer and Modood. Journal of Intercultural Studies, 33(2), 211-216.

https://doi.org/10.1080/07256868.2012.649528

Lebow, R. (2007). Classical Realism. In T. Dunne, M. Kurki \& S. Smith (Eds.), International Relations Theories: Discipline and Diversity. Oxford University Press.

Maoz, Z. (2011). Networks of Nations. The evolution, structure, and impact of international networks, 1816-2001. Cambridge University Press. Mearsheimer, J. (2007). Structural Realism. In T. Dunne, M. Kurki \& S. Smith (Eds), International Relations Theories: Discipline and Diversity. Oxford University Press.

Meer, N., \& Modood, T. (2012). How does Interculturalism Contrast with Multiculturalism? Journal of Intercultural Studies, 33(2), 175-196. https://doi.org/10.1080/07256868.2011.618266

Swartz, D. (2013). Symbolic Power, Politics, and Intellectuals: The Political Sociology of Pierre Bourdieu. The University of Chicago Press.

Sze, F., \& Powell, D. (2004). Interculturalism: Exploring Critical Issues. Inter-disciplinary Press.

Vertovec, S., \& Wessendorf, S. (2010). Introduction: Assessing the backlash against multiculturalism in Europe. In S. Vertovec \& S. Wessendorf (Eds.), The Multiculturalism Backlash. Routledge. 
Wallerstein, I. (1990). Culture as the Ideological Battleground of the Modern World-System. Theory, Culture and Society, 7(2), 31-55.

https://doi.org/10.1177/026327690007002003

Waltz, K. (1990). Realist thought and neorealist theory. Journal of International Affairs, 44 (1), 21-38.

Wasserman, S., \& K. Faust (1994). Social Network Analysis. Methods and Applications. Cambridge University Press.

Weber, C. (2009). International Relations Theory: A Critical Introduction, 3rd Ed. London: Routledge.

Weedon, C. (1987). Feminist Practice and Poststructuralist Theory. Blackwell.

Wendt, A. (1992). Anarchy is what states make of it: the social construction of power politics. International Organization, 46(2), 391-425. https://doi.org/10.1017/S0020818300027764

Wendt, A. (1994). Collective Identity Formation and the International State. American Political Science Review, 88(2), 384-396. https://doi.org/10.2307/2944711

Wendt, A. (1995). Constructing International Politics. International Security, 20(1), 71-81. https://doi.org/10.2307/2539217

Wendt, A. (1999). Social Theory of International Politics. Cambridge University Press.

Livia García-Faroldi is Full Professor of Sociology at the Faculty of Communication, University of Málaga.

Valeria Bello is Associate Professor in Sociology at the Blanquerna School of Communications and International Relations, University Ramon Llull.

Email:1garcia@uma.es 